\title{
Pemilihan Kualitas Kayu Terbaik Pada Pt. Rumah Kayu Kita Dengan Metode Weighted Product
}

\author{
${ }^{1}$ Titin Kristiana, ${ }^{2}$ Firman Alfian \\ Sekolah Tinggi Manajemen Informatika dan Komputer Nusa Mandiri, \\ Jl. Jatiwaringin No. 2, Cipinang Melayu, Makasar Jakarta Timur, Indonesia \\ ${ }^{1}$ titin.tka@nusamandiri.ac.id ${ }^{2}$ firmanal1911@bsi.ac.id
}

\begin{tabular}{l} 
Article Info \\
\hline Article history: \\
Received, 1/10/2020 \\
Revised, 4/11/2020 \\
Accepted, 19/11/2020 \\
\hline Kata Kunci: \\
Sistem Pendukung Keputusan \\
Kayu \\
Weighted Product \\
Fuzzy Multi Attribut Decision \\
Making (MADM)
\end{tabular}

\section{Keywords:}

Decision Support Systems

Wood

Weighted Product

Fuzzy Multi Attribut Decision Making (MADM)

\begin{abstract}
ABSTRAK
Sistem Pendukung Keputusan ditujukan untuk keputusan yang memerlukan penilaian atau untuk keputusan yang sama sekali tidak dapat didukung oleh algoritma. Sistem Pendukung Keputusan meluas dengan cepat, dari sekedar alat pendukung personal menjadi komoditas yang dipakai bersama. Dengan terus berkurangnya produksi kayu hutan alam maka kayu olahan menjadi alternatif bagi masyarakat untuk memasok kebutuhan kayu. Pada PT. RUMAH KAYU KITA kualitas kayu menjadi salah satu kebutuhan utama dalam pemilihan kayu terbaik untuk digunakan dalam berbagai kebutuhan. Metode Weighted Product yang memanfaatkan beberapa pilihan alternatif yang ada, khususnya Fuzzy Multi Attribut Decision Making (MADM) sebagai dasar perhitungan yang berguna untuk pengambil keputusani
\end{abstract}

\begin{abstract}
Decision Support Systems are intended for decisions that require assessment or for decisions that cannot be supported by an algorithm. Decision Support Systems spread rapidly, from more personal support tools to shared commodities. With the continued decline in natural forest timber production, processed wood is an alternative for the community to supply timber. At PT. RUMAH KAYU KITA the quality of wood is one of the main needs in choosing the best wood for use in various needs. Weighted Product Method that utilizes several alternative options available, especially Fuzzy Multi Attribute Decision Making (MADM) as a basis for calculations that are useful for decision makers
\end{abstract}

This is an open access article under the CC BY-SAlicense.

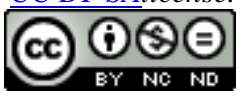

\section{Penulis Korespondensi}

${ }^{1}$ Titin Kristiana

Program Studi Sistem Informasi,

Sekolah Tinggi Manajemen Informatika dan Komputer Nusa Mandiri

Email: titin.tka@nusamandiri.ac.id

\section{PENDAHULUAN}

Kebutuhan manusia akan kayu terus meningkat, walaupun produksi hutan alam untuk menghasilkan kayu terus berkurang dari tahun ke tahun. Berbagai kegunaannya di dalam kehidupan manusia, membuat fungsi kayu semakin berkembang dan beragam sesuai sifat alami kayu itu sendiri. Jumlah persediaan kayu yang tersedia di berbagai industri pengolahan kayu saat ini sangat terbatas sehingga mengakibatkan ketidak tetapan harga kayu jika dibandingkan pada tahun 1980-an dan 1990-an dimana di Indonesia konsentrasi industri kayu mendapat sebutan sebagai sentra industri.

Dengan terus berkurangnya produksi kayu hutan alam maka kayu olahan menjadi alternatif bagi masyarakat untuk memasok kebutuhan kayu. Mutu dari suatu jenis kayu ditentukan oleh sifat fisiknya seperti warna, tekstur, serat, bau dan sifat - sifat pengerjaan seperti sifat pengovenan, pemboran, dan pengampelasan. Dalam satu hal, kualitas mungkin ditentukan dari kerapatan, penampilan, cacat kayu yang terkandung seperti mata kayu, miring serat, lubang gerek yang akan mempengaruhi pengerjaan dan pemakaiannya.

Metode Weighted Product ini dipilih karena mampu memilih alternatif terbaik dari sejumlah alternatif. Dalam hal ini alternatif yang dimaksud adalah kualitas buah rambutan yang terbaik berdasarkan kriteria-kriteria yang ditentukan dengan langkah-langkah metode Weigted Product yang sederhana, mudah dipahami, efektif dan efesien. Dimana nilai setiap atribut 
JSAI : Journal Scientific and Applied Informatics

Vol. 3, No. 3, November 2020, hal. 70 76

E-ISSN: 2614-3054; P-ISSN: 2614-3062, accredited by Kemenristekdikti, Sinta 5

DOI: 10.36085

(kriteria) harus dipangkatkan dulu dengan bobot atribut (kriteria) yang bersangkutan kemdian dilanjutkan dengan cara Descending (urutan nilai dari yang terbesar).

\section{METODE PENELITIAN}

\section{A. Sistem Pendukung Keputusan}

Sistem Pendukung Keputusan digunakan sebagai alat bantu bagi para pengambil keputusan untuk memperluas kapabilitas para pengambil keputusan, namun tidak untuk menggantikan penilaian para pengambil keputusan. SPK ditujukan untuk keputusan yang memerlukan penilaian atau untuk keputusan yang sama sekali tidak dapat didukung oleh algoritma. SPK meluas dengan cepat, dari sekedar alat pendukung personal menjadi komoditas yang dipakai bersama[1].

\section{B. Kayu}

Kayu adalah salah satu bahan bangunan yang sudah lama dikenal oleh masyarakat dan merupakan bahan yang sangat sering dipergunakan, termasuk sebagai bahan konstruksi bangunan, yang berfungsi sebagai struktur dan non struktur bangunan. Di indonesia terdapat banyak sekali jenis kayu yang berbeda sifat-sifat nya (kayu), sehingga dalam pemilihan atau penentuan jenis untuk tujuan penggunaan sesuai dengan yang diinginkan, apakah untuk kontruksi (struktur), atau sebagai bahan untuk kebutuhan seni non struktur.

\section{Fuzzy Multi Attribut Decision Making (FMADM)'}

Fuzzy Multiple Attribute Decision Making (FMADM) adalah suatu metode yang digunakan untuk mencari alternatif optimal dari sejumlah alternatif dengan kriteria tertentu. Inti dari FMADM adalah menentukan nilai bobot untuk setiap atribut, kemudian dilanjutkan dengan proses perangkingan yang akan menyeleksi alternatif yang sudah diberikan[2].

Ada beberapa metode yang dapat digunakan untuk membantu menyelesaikan masalah FMADM antara lain[3]:

1. Simple Addtive weighting Method (SAW)

2. Weighted Product (WP)

3. Electre

4. Technique for Order Preference by Similarity to Ideal Solution (TOPSIS)

5. Analytic Hierarchy Process (AHP)

\section{Weighted Product}

Metode Weighted Product (WP) adalah salah satu metode dalam sistem pengambilan keputusan dimana pengambilan sebuah keputusan dapat dilakukan secara lebih cepat dan tepat, sesuai dengan kriteria yang di inginkan atau setidaknya mendekati kriteria yang diinginkan[4].

Metode Weighted Product memiliki langkah-langkah sebagai berikut[5]:

1. Penentuan Kriteria.

2. Penilaian bobot kepentingan tiap kriteria.

3. Penentuan range nilai tiap kriteria.

4. Penilaian tiap alternatif menggunakan semua kriteria dengan penentuan range nilai yang disediakan menunjukan seberapa besar kepentingan antar kriteria.

5. Dari data penelitian tiap bobot kriteria dan nilai alternatif dibuat matriks keputusan.

Preferensi untuk alternatif $A_{i}$ diberikan sebagai berikut:

Keterangan:

$$
S_{i}=\prod_{j=i}^{n} x_{i j} w^{j}
$$

$\begin{array}{ll}\mathrm{S} & \text { : Preferensi alternatif dianalogikan } \\ & \text { sebagai vektor S } \\ \mathrm{X} & : \text { Nilai kriteria } \\ \mathrm{W} & \text { : Bobot kriteria atau sub kriteria } \\ \mathrm{i} & \text { : Alternatif (dimana } \mathrm{i}=1,2 \ldots . . \mathrm{n}) \\ \mathrm{j} & : \text { Kriteria } \\ \mathrm{n} & : \text { Banyaknya kriteria }\end{array}$

Dimana $\sum w j=1$, variable $w_{j}$ adalah pangkat bernilai positif untuk atribut keuntungan dan bernilai negatif untuk atribut biaya.

Preferensi relatif dari setiap alternatif, diberikan oleh persamaan: 
Keterangan:

$$
V_{i}=\frac{\prod_{j=1}^{n} X_{i j} W_{j}}{\prod_{j=1}^{n}\left(X_{i j} *\right) W_{j}}
$$

$\mathrm{V} \quad$ : Preferensi alternatif dianalogikan sebagai vektor $\mathrm{V}$

$\mathrm{X} \quad$ : Nilai kriteria

i : Alternatif

j : Kriteria

n : : Banyaknya kriteria

* : : Banyaknya kriteria yang telah nilai pada vektor $\mathrm{S}$

\section{HASIL DAN ANALISIS}

\section{A. Tahapan Intelejen (Intelligence)}

Kriteria 1 : Harga (K1). Ukuran terbagi menjadi empat yaitu:

1. Sangat Mahal

2. Mahal

3. Murah

4. Sangat Murah

Kriteria 2 : Tekstur (K2). Ukuran terbagi menjadi tiga yaitu:

1. Kasar

2. Sedang

3. Halus

Kriteria 3 : Kandungan Air (K3). Ukuran terbagi menjadi tiga yaitu:

1. Basah

2. Sedikit Basah

3. Kering

Kriteria 4 : Ukuran (K4). Ukuran terbagi menjadi empat yaitu:

1. Sangat Tebal

2. Tebal

3. Sedang

4. Tipis

\section{B. Bobot dan Kriteria}

Tabel IV.1.

Keterangan Kriteria

\begin{tabular}{ll}
\hline Kriteria & Keterangan \\
\hline C1 & Harga \\
C2 & Tekstur \\
C3 & Kandungan Air \\
C4 & Ukuran \\
\hline
\end{tabular}

Selanjutnya Pengambil Keputusan memberikan bobot preferensi untuk masing-masing kriteria sebagai W (bobot awal) dapat dilihat sebagai berikut:

Tabel IV.2.

Bobot Serta Keterangan

\begin{tabular}{llc}
\hline Kriteria & Range & Bobot \\
\hline C1 & Sangat Baik & 4 \\
C2 & Baik & 3 \\
C3 & Kurang & 2 \\
C4 & Buruk & 1 \\
\hline
\end{tabular}


JSAI : Journal Scientific and Applied Informatics

Vol. 3, No. 3, November 2020, hal. 70 76

E-ISSN: 2614-3054; P-ISSN: 2614-3062, accredited by Kemenristekdikti, Sinta 5

DOI: 10.36085

Dari masing-masing kriteria tersebut akan ditentukan bobot-bobotnya. Pada bobot terdiri dari empat bilangan fuzzy, yaitu Buruk (B1), Kurang (K1), Baik (B2), Sangat Baik (SB).

Buruk Kurang Baik Sangat Baik
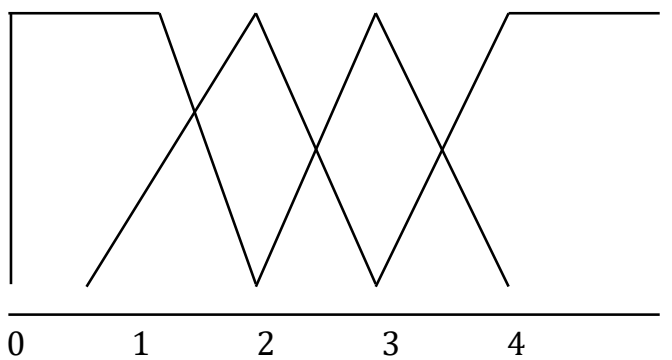

Gambar 1. Bobot

C. Pembobotan Fuzzy

Pembobotan Fuzzy Untuk Kriteria Harga

Tabel IV.3.

Menentukan Kriteria Harga

\begin{tabular}{lll}
\hline Range & Nilai Fuzzy & Bobot \\
\hline Sangat Mahal & Sangat Baik & 4 \\
Mahal & Baik & 3 \\
Murah & Kurang Baik & 2 \\
Sangat Murah & Buruk & 1 \\
\hline
\end{tabular}

Pembobotan Fuzzy Untuk Kriteria Tekstur

Tabel IV.4.

Menentukan Kriteria Tekstur

\begin{tabular}{lll}
\hline Range & Nilai Fuzzy & Bobot \\
\hline Kasar & Sangat Baik & 4 \\
Sedang & Baik & 3 \\
Halus & Kurang Baik & 2 \\
\hline
\end{tabular}

Pembobotan Fuzzy Untuk Kriteria Kandungan Air

Tabel IV.5.

Menentukan Kriteria Kandungan Air

\begin{tabular}{lll}
\hline Range & Nilai Fuzzy & Bobot \\
\hline Basah & Sangat Baik & 4 \\
Sedikit Basah & Baik & 3 \\
Kering & Kurang Baik & 2 \\
\hline
\end{tabular}

Pembobotan Fuzzy Untuk Kriteria Ukuran

Tabel IV.6.

Menentukan Kriteria Ukuran

\begin{tabular}{lll}
\hline Range & Nilai Fuzzy & Bobot \\
\hline Sangat Tebal & Sangat Baik & 4 \\
Tebal & Baik & 3 \\
Sedang & Kurang Baik & 2 \\
Tipis & Buruk & 1 \\
\hline
\end{tabular}


Alternatif Kayu

Tabel IV.7.

Lanjutan Alternatif Kayu

\begin{tabular}{|c|c|c|c|c|c|}
\hline \multirow{2}{*}{ No } & \multirow{2}{*}{ Alternatif } & \multicolumn{4}{|c|}{ Kriteria } \\
\hline & & C1 & C2 & $\mathrm{C3}$ & C4 \\
\hline 1 & Kempas & $\begin{array}{l}\text { Sangat } \\
\text { Murah }\end{array}$ & Halus & $\begin{array}{c}\text { Sedikit } \\
\text { Basah }\end{array}$ & Tipis \\
\hline 2 & Sonokeling & Mahal & Kasar & Basah & $\begin{array}{c}\text { Sangat } \\
\text { Tebal }\end{array}$ \\
\hline 3 & Jati & $\begin{array}{l}\text { Sangat } \\
\text { Mahal }\end{array}$ & Kasar & $\begin{array}{l}\text { Sedikit } \\
\text { Basah }\end{array}$ & Tebal \\
\hline 4 & Merbau & Mahal & Kasar & Basah & Tebal \\
\hline 5 & Mahoni & $\begin{array}{l}\text { Sangat } \\
\text { Murah }\end{array}$ & Sedang & $\begin{array}{c}\text { Sedikit } \\
\text { Basah }\end{array}$ & Tipis \\
\hline 6 & Ulin & $\begin{array}{l}\text { Sangat } \\
\text { Mahal }\end{array}$ & Kasar & Basah & $\begin{array}{c}\text { Sangat } \\
\text { Tebal }\end{array}$ \\
\hline 7 & Bangkirai & Mahal & Kasar & Kering & Sedang \\
\hline 8 & Sungkai & $\begin{array}{l}\text { Sangat } \\
\text { Murah }\end{array}$ & Sedang & $\begin{array}{c}\text { Sedikit } \\
\text { Basah }\end{array}$ & Sedang \\
\hline 9 & Wild Teak & $\begin{array}{l}\text { Sangat } \\
\text { Murah }\end{array}$ & Sedang & Kering & Sedang \\
\hline
\end{tabular}

Rating Kecocokan Alternatif pada setiap Kriteria

Tabel IV.8.

Rating Kecocokan Alternatif pada Kriteria

\begin{tabular}{cccccc}
\hline \multirow{2}{*}{ No } & \multirow{2}{*}{ Alternatif } & \multicolumn{4}{c}{ Kriteria } \\
& & C1 & C2 & C3 & C4 \\
\hline 1 & Kempas & 1 & 2 & 3 & 1 \\
2 & Sonokeling & 3 & 4 & 4 & 4 \\
3 & Jati & 4 & 4 & 3 & 3 \\
4 & Merbau & 3 & 4 & 4 & 3 \\
5 & Mahoni & 1 & 3 & 3 & 1 \\
6 & Ulin & 4 & 4 & 4 & 4 \\
7 & Bangkirai & 3 & 4 & 2 & 2 \\
8 & Sungkai & 1 & 3 & 3 & 2 \\
9 & Wild Teak & 1 & 3 & 2 & 2 \\
\hline
\end{tabular}

\section{Penerapan metode WP}

Adapun langkah penyelesaian dengan metode Weighted Product sebagai berikut:

1. Tentukan bobot awal dari setiap kriteria

Adapun bobot awal dari setiap kriteria adalah $W=(3,4,2,1)$.

2. Perbaiki bobot dengan cara $W_{j}=\frac{w}{\sum w}$ sehingga $\sum w j=1$

Adapun cara penyelesaian sebagai berikut:

$$
\begin{aligned}
& \mathrm{W}_{1}=\frac{3}{4+3+2+1}=\frac{3}{10}=0,3 \\
& \mathrm{~W}_{2}=\frac{4}{4+3+2+1}=\frac{4}{10}=0,4
\end{aligned}
$$


JSAI : Journal Scientific and Applied Informatics

Vol. 3, No. 3, November 2020, hal. 70 76

E-ISSN: 2614-3054; P-ISSN: 2614-3062, accredited by Kemenristekdikti, Sinta 5

DOI: 10.36085

$$
\begin{aligned}
& \mathrm{W}_{3}=\frac{2}{4+3+2+1}=\frac{2}{10}=0,2 \\
& \mathrm{~W}_{4}=\frac{1}{4+3+2+1}=\frac{1}{10}=0,1
\end{aligned}
$$

3. Menghitung Vektor S dengan cara berikut ini:

$$
S_{i}=\prod_{j=i}^{n} x_{i j} w^{j}
$$

Dimana $\mathrm{W}_{\mathrm{j}}$ adalah pangkat bernilai positif untuk atribut keuntungan dan bernilai negatif untuk atribut biaya. Adapun penyelesaiannya sebagai berikut:

$$
\begin{aligned}
& S_{1}=\left(1^{-0,3}\right)\left(2^{0,4}\right)\left(3^{0,2}\right)\left(1^{0,1}\right)=1,6437 \\
& S_{2}=\left(3^{-0,3}\right)\left(4^{0,4}\right)\left(4^{0,2}\right)\left(4^{0,1}\right)=1,8978 \\
& S_{3}=\left(4^{-0,3}\right)\left(4^{0,4}\right)\left(3^{0,2}\right)\left(3^{0,1}\right)=1,5969 \\
& S_{4}=\left(3^{-0,3}\right)\left(4^{0,4}\right)\left(4^{0,2}\right)\left(3^{0,1}\right)=1,8441 \\
& S_{5}=\left(1^{-0,3}\right)\left(3^{0,4}\right)\left(3^{0,2}\right)\left(1^{0,1}\right)=1,9330 \\
& S_{6}=\left(4^{-0,3}\right)\left(4^{0,4}\right)\left(4^{0,2}\right)\left(4^{0,1}\right)=1,7407 \\
& S_{7}=\left(3^{-0,3}\right)\left(4^{0,4}\right)\left(2^{0,2}\right)\left(2^{0,1}\right)=1,5414 \\
& S_{8}=\left(1^{-0,3}\right)\left(3^{0,4}\right)\left(3^{0,2}\right)\left(2^{0,1}\right)=2,0716 \\
& S_{9}=\left(1^{-0,3}\right)\left(3^{0,4}\right)\left(2^{0,2}\right)\left(2^{0,1}\right)=1,9101
\end{aligned}
$$

4. Menentukan Preferensi $V_{i}$ untuk perangkingan:

$$
V_{i}=\frac{\prod_{j=1}^{n} X_{i j} W_{j}}{\prod_{j=1}^{n}\left(X_{i j} *\right) W_{j}}
$$

Dimana nilai $\mathrm{V}_{\mathrm{i}}$ yang terbesar adalah alternatif yang terpilih. Adapun cara penyelesaiannya sebagai berikut:

$$
\begin{aligned}
& \mathrm{V}_{1}=\frac{1,6437}{13,4847}=0,1015 \\
& \mathrm{~V}_{2}=\frac{1,8978}{13,4847}=0,1172 \\
& \mathrm{~V}_{3}=\frac{1,5969}{13,4847}=0,0987 \\
& \mathrm{~V}_{4}=\frac{1,8441}{13,4847}=0,1139 \\
& \mathrm{~V}_{5}=\frac{1,9330}{13,4847}=0,1194 \\
& \mathrm{~V}_{6}=\frac{1,7407}{13,4847}=0,1075 \\
& \mathrm{~V}_{7}=\frac{1,5414}{13,4847}=0,0952 \\
& =0,1280
\end{aligned}
$$




$$
V_{9}=\frac{13,4847}{13,4847}=0,1180
$$

Hasil Perangkingan Alternatif

Tabel IV.9.

Perangkingan untuk Alternatif

\begin{tabular}{clcc}
\hline Vi & Alternatif & Nilai & Rangking \\
\hline V1 & Kempas & 0,1050 & 7 \\
V2 & Sonokeling & 0,1172 & 4 \\
V3 & Jati & 0,0987 & 8 \\
V4 & Merbau & 0,1139 & 5 \\
V5 & Mahoni & 0,1194 & 2 \\
V6 & Ulin & 0,1075 & 6 \\
V7 & Bangkirai & 0,0952 & 9 \\
V8 & Sungkai & 0,1280 & 1 \\
V9 & Wild Teak & 0,1180 & 3 \\
\hline
\end{tabular}

Dari perangkingan tabel 4.9. maka perlu diketahui bahwa kayu Sungkai merupakan alternatif dari beberapa alternatif yang ada dalam pemilihan kualitas kayu terbaik dengan perolehan nilai 0,1280

\section{KESIMPULAN}

Kesimpulan yang diperoleh dari penelitian ini, yaitu:

1. Metode Weighted Product dapat membantu dalam mengambil keputusan untuk menentukan tingkatan kayu sesuai dengan kriteria-kriteria yang sudah ditentukan.

2. Penerapan metode Weighted Product cukup mudah digunakan untuk melakukan penilaian dalam menentukan kayu dengan kualitas terbaik karena penyelesaiannya cukup sederhana. Perhitungan Weighted Product ada 4 tahap yaitu, penentuan nilai bobot $\mathrm{W}$, perbaikan bobot $\mathrm{W}$, penentuan nilai Vektor S, serta penentuan nilai Vektor V.

3. Dari berbagai alternatif kayu, kayu sungkailah menjadi salah satu alternatif dengan kualitas terbaik.

\section{REFERENSI}

[1] Rusman, A."Logika fuzzy tahani sistem penunjang keputusan penentuan lulusan terbaik". Jurnal Geodesi Undip, 6(2), 2355-5920. 2016 https://doi.org/10.1123/IJNS.V2I4.181

[2] Khairina, D. M., Ivando, D., \& Maharani, S. 47-1-139-1-10-20160929, 8(1), hlm 1-8.2016

[3] Manik, A. R. S., Nurhadiyono, B., \& Rahayu, Y. "Implementasi Metode Weighted Product ( Wp ) Dalam Sistem Pendukung Keputusan Untuk Menyeleksi Penerima Beras Masyarakat Miskin (Raskin)”. Techno.COM, 14(2), $109-114.2015$

[4] Yoga Handoko Agustin \& Hendra Kurniawan. "Sistem Pendukung Keputusan Dalam Penilaian Kinerja”. 2016

[5] Stephano, A., \& Sari, Puspita, R. "Sistem Pendukung Keputusan dalam Penerimaan Karyawan Menggunakan Metode Weighted Product”. Jurnal PROSIDING SEMINAR NASIONAL SISFOTEK, 01(03), 14-25. 2018

[6] Darmawan, D "Penelitian Kuantitatif. In Metode Penelitian Kuantitatif “(p. 325). PT. Remaja Rosdakarya. . (2019). 